\title{
FLOWERING CURVES AND THE SUMMER-GAP MYSTERY
}

\author{
Geoffrey Harper ${ }^{1}$ \& Elizabeth Rogers ${ }^{2}$
}

\begin{abstract}
Results from year-round weekly monitoring of 93 taxa (179 accessions) at the Royal Botanic Garden Edinburgh (RBGE) are presented in the form of flowering curves. These are provisionally grouped into classes, and hypotheses are suggested to explain the different patterns. Attention is drawn to a prominent 'summer gap' in flowering in some species, and possible explanations for the gap are discussed.
\end{abstract}

\section{INTRODUCTION}

This paper presents a provisional interpretation of weekly observations of flowering recorded by the Weekly Phenology Project at RBGE. Weekly monitoring was first undertaken in the period 1906-1938 (Harper et al., 2004), and was restarted as a pilot project from December 2002 to early April 2004. In the pilot project flowering was recorded merely as presence or absence. A team of volunteers was later assembled and they have conducted the current Weekly Project since January 2005. Early results from this project were published in Sibbaldia No. 5 (Harper \& Morris, 2007), in which a "mediterranean-type" of flowering pattern is described, and Sibbaldia No. 6 (Blades et al., 2008), which describes methods of observation.

In Sibbaldia No. 2 (Harper et al., 2004) it was recommended that extensive phenological surveys should gather a limited amount of carefully selected objective information on a wide range of taxa, and that there should be a clear purpose in designing the project. It has been realised in the course of year-round weekly monitoring at RBGE that, with monitoring generally conducted on Wednesdays, the method is not very suitable for collecting sensitive data on phenological events in the short term. This is because the Wednesday monitoring will occur on a different date each year, generally advancing by one calendar day per year with a six-day change in the other direction every six years or so, and with leap years adding further complications. Twenty to thirty years of observations would probably be needed before standard statistical methods could be usefully employed on first-flower dates (FFDs) and similar parameters. In addition some years have 53 Wednesdays, instead of the usual 52, and this causes problems in compiling the Aniśko diagrams (see below). Accordingly, the weekly monitoring is used mainly to gain a general idea of the shape of the flowering curve, and of the variation from year to year, in each of the accessions and taxa monitored. This 'natural-history' kind

1. Geoffrey Harper, to whom correspondence should be addressed, is a Research Associate at Royal Botanic Garden Edinburgh. Address: 20A Inverleith Row, Edinburgh EH3 5LR. E-mail: g.harper@rbge.org.uk

2. Elizabeth Rogers is a retired lecturer in Biological Sciences at Edinburgh University, now living in Devon. 
of description is invaluable in allowing phenomena to be identified which merit more detailed scientific investigation, in stimulating hypotheses and in providing material for a classification of flowering behaviour into functional groups - which is the main purpose of this article.

An additional benefit relates to the concern that studying FFDs, on which RBGE's Daily Project concentrates, may sometimes give a poor indication of when mass or peak flowering occurs. In many cases FFDs do in fact correlate satisfactorily with subsequent flowering behaviour, but it was discovered early on that Tilia, Ribes and a few other taxa tended to begin flowering erratically, with early flowers sometimes deformed or falling before opening fully. In these cases special criteria were adopted, such as recording the first date when ten flowers were open or ten inflorescences (Ribes) with at least one flower open on each. It will be clear from some of the diagrams in this paper that FFD does not bear much relation to mass flowering, but this does not mean that FFD is not a parameter worth studying in its own right. In these cases the timing of peak or mass flowering would need to be measured independently.

The current phenology projects at RBGE began in January 2002 with daily observations of FFD. Taxa were selected for this project on the basis of various criteria, to include (a) species studied at RBGE in the 19th century; (b) a range of native species; (c) representatives of families in which RBGE specialises; (d) species studied in phenology projects in other parts of the country; and (e) representatives of early, late, short-duration and long-duration flowering. When the Weekly Project was established species were transferred to it from the Daily Project where it was thought that year-round monitoring would yield valuable extra information. Given this complicated history, it would be misleading to consider our set of taxa as representative of the temperate, global or any other flora.

Included in this study were 179 accessions and 93 taxa, for which there are adequate observations to draw meaningful histograms. We believe that this is a pioneering study since we are not aware of any other botanic garden using similar methods. Perhaps the only precedent is the study by Tomasz Aniśko (Aniśko, 2008). On the strength of our provisional results we recommend that other botanic gardens conduct similar studies with a view to discovering the full range of variation in flowering patterns, and estimating the relative frequencies of the different patterns in various parts of the world.

\section{THE DIAGRAMS}

In the diagrams of the flowering patterns the 52 weeks of the year are arranged from left to right (ignoring week 53), sometimes from January to December and sometimes from week 27 to week 26 in the following calendar year. The bar just below the week numbers shows relative daylength, with dark and white cells indicating winter and summer respectively. The reason for the two arrangements is that sometimes one and sometimes the other is best for displaying the shape of the flowering curve.

The summer solstice generally falls in week 25, and week 26 marks the end of the first half of the year (end of June). It was noticed that accessions flowering through the cold 
season of the year very often take a break from flowering, even just a short one, at the end of June, and so week 27 was usually found to be a convenient start for the winter-centred diagrams. This first alerted us to the 'summer-gap mystery', which is discussed below.

Below the daylength bar, individual records for each of several years are shown as grey histograms. The height of each weekly column indicates the quantity of flowers, mainly using the 'tick, 1-4' method but sometimes using counts on the scale 1,2 and so on up to 9 , then $10+, 15+, 20+$ and so on up to $50+$ (both methods are described in Blades et al., 2006). Comparison of column heights from one year to the next is not reliable, but is accurate enough to give a good idea of when peak or mass flowering occurs within each year. A question mark in a cell usually shows where observations were not made because of bad weather.

The blue histogram at the bottom is called an 'Aniśko diagram', after the use of such diagrams in Aniśko (2008). In that study, conducted at Longwood Gardens near Philadelphia, snow ruled out monitoring during the winters, with the result that a rather limited range of flowering curves was revealed. In our study we have used dark blue to show flowering as ten or more flowers (or sometimes inflorescences), with pale blue cells added to represent flower/inflorescence counts of less than ten. This distinction can be objectively measured, and gives useful information about the capacity of a plant to flower as distinct from the actual production of a substantial number of flowers. The height of each column shows the number of years in which flowering occurred in each week.

An important characteristic to note in these diagrams is the abruptness of the beginning and/or end of flowering. An abrupt 'cliff' at one or other end of the flowering period (such as the end of flowering in Fig. 4) indicates a high degree of synchronicity in the phenological event. In contrast a gradual 'slope' up to or down from the maximum column height (such as the beginning of flowering in Fig. 4) indicates a poorly synchronised phenological event. This feature can be used to suggest possible mechanisms regulating the timing of the event.

Sometimes results from only a few years are shown in the diagrams; this is usually because results from earlier years were recorded using a different method, such as presence or absence of flowering, which does not lend itself to histograms. In no case, however, do results from the years not shown conflict seriously with the flowering curve in the Aniśko diagrams.

It will be clear from the results presented here that there is sometimes considerable intra-taxon variation in flowering behaviour, even to the extent that different accessions of the same taxon may be classified in different groups. Where necessary, accessions are distinguished by the last three characters in the RBGE accession number; for example, 'Arabis alpina (56A)' refers to the plant with the accession number '19511056A'.

\section{PROVISIONAL CLASSIFICATION AND HYPOTHESIS}

The main aim of this article is to attempt a provisional classification of flowering curves, so far as possible by describing natural clusters separated by discontinuities. However, 
one large class is divided into three sub-classes using arbitrary values of one character (length of flowering period), since there are probably no convenient discontinuities in the wide range of flowering-period durations. Altogether there are three classes, distinguished by the degree of symmetry of the flowering curve and by the number of flowering periods, and each class is divided into a number of sub-classes. It is assumed that there is no relation between the flowering-curve classification and the taxonomic classification of the monitored taxa, but any correspondence between the two classifications that emerges will be of interest.

It is known that flowering behaviour, and therefore also the characteristics of the flowering curves as represented in the histograms, are determined by a variety of mechanisms, as discussed in Harper (2010). For spring-flowering plants, thermal acceleration of development is usually important, measured using thermal time or correlation of FFDs with temperature. For many of them chilling is also important. Photoperiod regulation is probably significant in some species, although not much is known about it in many species since it cannot be readily detected using rapid-survey methods. Körner (2006) points out that some trees respond to daylength in both spring and autumn, and it is possible that this is a widespread phenomenon. Photoperiod may be a permissive factor, a given minimum or maximum daylength (or nightlength) being necessary for floral or inflorescence initiation to occur. Where a restricted range of daylengths is permissive, with perhaps very short and very long daylengths inhibiting initiation, one might expect two flowering seasons in each year, with summer and winter gaps in flowering displaced somewhat later than the summer and winter solstices to take account of the development period from initiation to flower opening.

Other mechanisms include temperature thresholds, temperature-dependent resource switching and differential mortality of buds. In some taxa the duration of a flowering period may be largely determined by individual flower longevity, itself influenced by such factors as temperature or pollination success; but duration of the flowering period may also be a function of the synchronicity with which flowers open.

\section{CLASS A: SYMMETRIC}

Taxa included in Class A are all those that do not show obvious asymmetry in the flowering curve and that have only one flowering period. Class A contains 110 accessions and 65 taxa, out of the 179 accessions and 93 taxa included in the whole study.

This group is labelled 'Symmetric' on the grounds that the flowering patterns lack significant deviations from a symmetric shape of the flowering curve. As will be seen below, this is something of a 'dustbin category' since several examples in Sub-class A3 do appear to deviate from symmetry, but the evidence is not yet sufficient for separation of these accessions in a separate group.

Sub-class A1 comprises accessions with short flowering periods lasting up to ten weeks. In the plants studied there are 50 accessions belonging to 26 taxa - Aesculus hippocastanum, A. parviflora, Agapanthus campanulatus, A. praecox, Corylus avellana 
(65A), Crocosmia pottsii (81A), Enkianthus campanulatus, Eucryphia glutinosa, Koelreuteria paniculata, Malus baccata hybrid, M. sieboldii, Muscari armeniacum (98A), Oxalis acetosella, Narcissus pseudonarcissus, Paeonia delavayi, Platycodon grandiflorum, Prunus hirtipes, Pyrus communis, Rhododendron decorum (03F, 12B), $R$. luteum, $R$. nobilis, $R . \times$ praecox, Ribes sanguineum, Sorbus 'Joseph Rock', S. reducta and Tulipa sylvestris. Most taxa flower in the first half of the year, but Agapanthus flowers later (in weeks 29-38).

It is unrealistic to expect any significant deviation from a more or less symmetric flowering curve when the flowering period is so short, although in principle the flowering curve might have a right-angle triangle shape if all the flowers burst open on the same day or fade simultaneously. Class A might informally be thought of as having 'explosive' flowering, in the sense that all flowers open more or less simultaneously and for a brief period only (although it is, in fact, quite rare for every single flower to be open at once on a bush or tree). It should be noted that the flowering periods are not well synchronised between years in the example illustrated (see Fig. 1), and this results in the Aniśko diagram suggesting a flowering period which is longer than actually occurs in any one year.

Typical examples of this sub-class are fruit trees in the Rosaceae and spring bulbs, and in both cases it is known that floral initiation generally occurs many months before flowering (Aniśko, 2008; Jackson, 2003). The A1 type of flowering curve is to be expected if a stock of flower buds has developed long before the flowering period, and then all flowers open when environmental conditions permit - after completion of such developmental stages such as dormancy, release from dormancy, photoperiod threshold, thermal acceleration of post-dormancy development and a thermal threshold releasing flower opening. The duration of the flowering period would then be a function of individual flower longevity and synchronicity of opening. Körner (2006) notes that apple is subject to photoperiod regulation. This may apply to Malus sieboldii, and thermal acceleration of development is likely in January and March-April before FFD, as well as resource switching in the previous June (Harper, 2010). So a sketch of a plausible developmental sequence determining the date of flowering in just this one tree in Edinburgh is beginning to emerge.

Sub-class A2 rather arbitrarily groups together accessions with flowering periods lasting from 11 to 25 weeks (see Fig. 2). There are 38 accessions belonging to 23 taxa Calluna vulgaris, Chaenomeles speciosus (10A), Corylus avellana (05A), Cornus mas, Cyclamen coum, C. hederifolium, Daphne bholua (39B), Eucryphia glutinosa (03B), E. lucida (06A), Fatsia japonica, Forsythia $\times$ intermedia (54C), Fuchsia magellanica (30B, 30C, 30D), Gentiana sino-ornata, Helleborus cyclophyllus, H. viridis, Lonicera periclymenum (53E), Mahonia $\times$ media (78A, 99A), Muscari armeniacum (82A), Pieris japonica, Primula vulgaris, Rhododendron anthosphaerum, $R$. barbatum and Tulbaghia violacea.

A wider range of hypotheses is probably needed to explain these flowering patterns. While the same general developmental sequence leading up to flowering may apply 


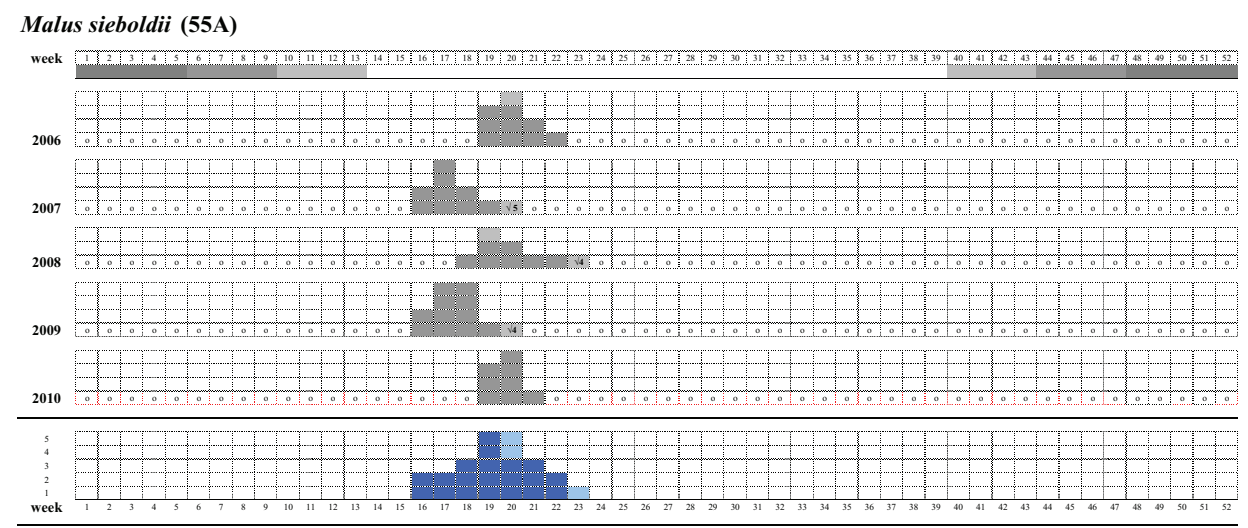

Fig. 1 Example of Sub-class A1: Malus sieboldii (55A).

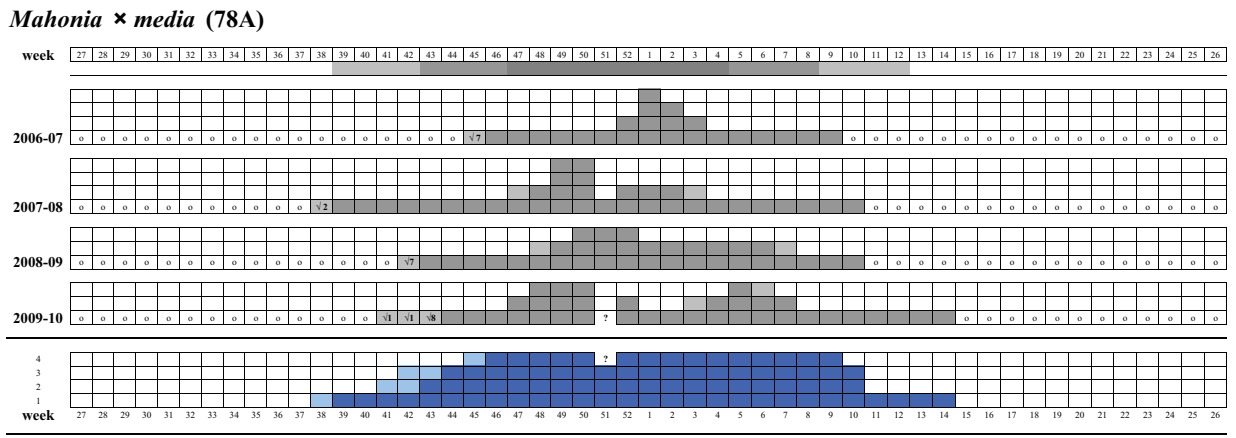

Fig. 2 Example of Sub-class A2: Mahonia $\times$ media $(78 \mathrm{~A})$.

as in the case of Sub-class A1, there are the additional possibilities of extreme lack of synchronicity in flower opening in a stock of pre-formed flowers, and/or a prolonged period of floral/inflorescence initiation during the flowering period, leading in principle to the possibility of endless flowering until some environmental trigger stops flowering or conditions are no longer suitable for flowering. The shape of the Aniśko diagram can sometimes suggest what is happening, but in these more or less symmetric flowering curves there is little clue as to what starts the flowering or brings it to a halt.

Incidentally, it should be noted that Fig. 2 shows a winter-flowering species which succeeds in flowering strongly through winter. In other cases there are often short gaps in winter, presumably resulting from short-term conditions, such as frost, snow or very low temperatures, which interrupt flowering. However flowering frequently resumes quite promptly, presumably due to flower buds that survived the inclement conditions. In this case, the long flowering period is due more to the staggered development of the flowers, rather than to simultaneous flowering of very long-lived flowers. 
Sub-class A3 contains the remaining 'symmetric' flowering curves (see Fig. 3), with flowering lasting between 26 and 52 (or 53) weeks. There are 36 accessions belonging to 17 taxa - Arabis alpina (56A, 56C), Armeria castellana, Chaenomeles speciosus (05A), Crinodendron patagua, Daphne bholua (36A, 80B), Erica cinerea, Fuchsia magellanica (19A), Hamamelis mollis, Iris unguicularis, Jasminum nudiflorum (06E), Lamium maculatum, Lonicera periclymenum (53B), Potentilla fruticosa, P. parvifolia, Tradescantia $\times$ andersoniana, Viburnum grandiflorum and $V$. tinus.

In plants with such extended flowering periods, sometimes all year round with only erratic gaps as in Arabis alpina (56A) (see Fig. 3), it is unlikely that hypotheses applicable to Sub-class A1 will apply. In many cases there is almost certainly a continual capacity for floral initiation, though in other cases this continuing capacity may be confined within a rather well-defined flowering period with a fairly synchronised beginning and/or end from year to year, suggestive of photoperiod regulation. Within the prolonged flowering period there may be some structure, suggesting a main flowering period, for instance in spring or early summer, with low-intensity or sporadic flowering in the rest of the flowering period. This is discussed further in relation to Fig. 5.

Figure 4 illustrates a case in which the Aniśko diagram suggests a fairly simple pattern, but the annual histograms show that in fact the individual flowering periods have a complex structure. Observations from more years are needed before it can be asserted with confidence that two or more mass-flowering periods are characteristic of each year's flowering. It is also not clear whether the mass flowerings in each year are synchronised with those in other years: if they are, then there appear to be three mass-flowering periods (also seen in Armeria castellana and Lamium maculatum). Meanwhile, this kind of example is retained in Sub-class A3, making it a rather untidy assemblage at present. If further observations confirm more than two flowering periods in these accessions, a new class could be described to accommodate them.

One further feature worth noting in Fig. 4 is that the start of flowering is highly variable, but flowering ends in a fairly synchronised manner (in weeks 19-20), as in

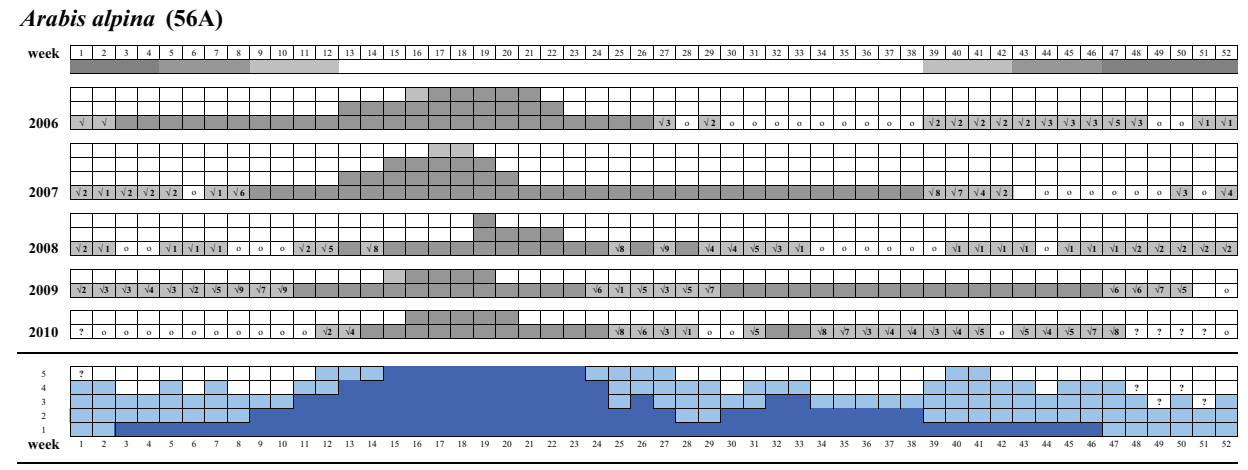

Fig. 3 Example of Sub-class A3: Arabis alpina (56A). 


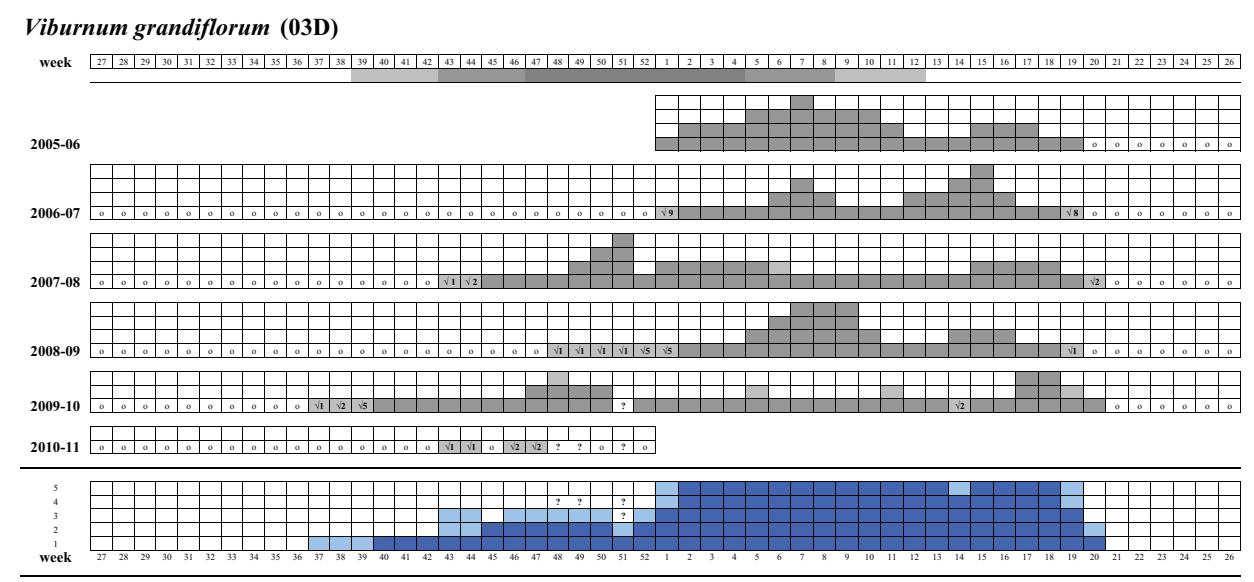

Fig. 4 Example of Sub-class A3: Viburnum grandiflorum (03D).

several other taxa, and this may be due to photoperiod regulation (Harper \& Morris, 2007). It is the synchronised end of flowering contrasting with the unsynchronised start that gives the Aniśko diagram a positive skew (see below), whereas the annual histograms have a more complex structure.

\section{CLASS B: SKEWED}

Skew refers to a simple asymmetric pattern in which the approximate bell shape of a typical symmetric flowering curve looks as though it has been 'pushed over' towards one end or the other of the distribution. A curve 'pushed over' to the right is said to be positively skewed (imagine a blancmange on a plate seen from the side in a suddenly decelerating car), and if 'pushed over' to the left is negatively skewed (the car is accelerating). As already noted, the Aniśko diagram in Fig. 4 is positively skewed, but for the purposes of describing Class B it is important to examine the annual histograms.

Sub-class B1 has a pronounced negative skew in most or all of the annual histograms (see Fig. 5). As already noted, a significant skew is likely to be revealed only in a flowering period lasting many weeks. The sub-class comprises 25 accessions in 18 taxa - Aster albescens, Cistus albidus, C. salviifolius, C. creticus, Crocosmia pottsii (42A), Erica tetralix, Fragaria californica, Hoheria sexstylosa, Hypericum cerastioides, $H$. forrestii, Hypericum 'Hidcote', Jasminum officinale, Lavandula angustifolia, Magnolia stellata, Rhododendron dauricum, R. lutescens (08A, 08D), Skimmia japonica and Stachys officinalis. (It has to be admitted that C. pottsii (42A) in this sub-class is not so different from C. pottsii (81A) in Sub-class A; the distinction between Class A and Class $\mathrm{B}$ is somewhat arbitrary where the skew is slight.)

It was suggested earlier that a skewed flowering curve might be considered as made up of a more or less symmetric main flowering period and a secondary 


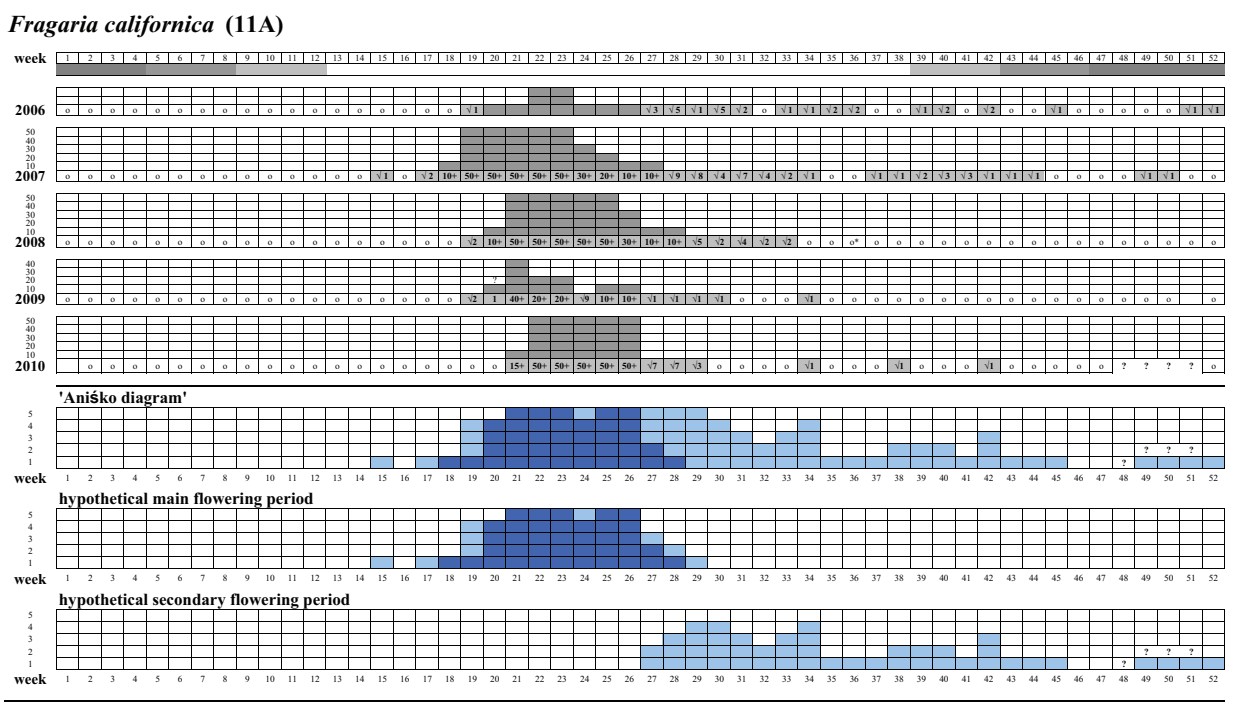

Fig. 5 Example of Sub-class B1: Fragaria californica (11A).

prolonged period of sporadic flowering. This is particularly easy to imagine in the case of Fragaria californica (11A) (see Fig. 5). Below the usual Aniśko diagram, the hypothetical main flowering period has been plotted on its own, together with the early records of fewer than ten flowers and few similar records arbitrarily assigned to the end of the main flowering period. At the bottom the remaining $<10$-flower records are shown, representing an extended period of low-level flowering. These flowers might possibly come from buds that undergo floral initiation later than that of the flowers in the main flowering period, and this late initiation may, in turn, be due to the buds having developed on new vegetative growth. This explanation is speculative, but it suggests questions that could be investigated further. For instance, it might be possible to separate the two kinds of flower morphologically, by the kind of shoot they are on, so that they can be counted separately, enabling the hypothetical diagrams to be replaced by objective observations. The two kinds of flowering could then be studied as separate phenomena.

Sub-class B2 consists of accessions showing the opposite pattern - a positive skew (see Fig. 6). This group consists of 15 accessions in 11 taxa - Choisya ternata, Daphne laureola, D. tangutica (92B), Eucalyptus gunnii, Forsythia $\times$ intermedia (55B, 57A, 58A), Helleborus cyclophyllus, Mahonia aquifolium, Muscari armeniacum (41A), Pieris japonica, Rhododendron dauricum (20A) and $R$. $\times$ praecox (94B). A striking feature of all these taxa is that the main flowering period occurs in late winter, spring or early summer. The 'tail' of the asymmetric flowering curve always extends back through winter and sometimes into autumn or even late summer. This sub-class corresponds to the 'mediterranean-type' described in Harper \& Morris (2007). 
As in the case of Sub-class B1, we can imagine the flowering curve comprising two superimposed hypothetical curves - a more or less symmetric main flowering period, occupying weeks 8-20 in the example in Figure 6, and the less intense flowering from mid-summer in the previous year. Comparison of all the accessions in this group suggests that the early flowers have somehow escaped the normal regulation that ensures that most flowers open in the main flowering period. The regulation mechanisms that come to mind are dormancy and release from dormancy. Scotland's mild winter climate, as compared with that in some of the home ranges of the species involved, makes it likely that thermal acceleration of development could occur at any time of year if other mechanisms permit. The diagrams in themselves do not suggest what happens before normal thermal acceleration of development begins, but it is possible either that dormancy is never established or that, if it is, autumn frosts are sufficient to break dormancy and so allow development to flowering in autumn or winter. Provisional results from the RBGE Daily Project indicate that chilling occurs in some species during quite a short period in autumn, so that autumn and winter flowering on this account is not at all implausible (Harper, 2008). This would not, however, explain flowering in mid summer, and in this case there may be a failure to establish dormancy in some of the flower buds.

It will be noted that all except one of the taxa in Sub-class B2 are non-native, the exception being Daphne laureola. This opens the possibility that the premature flowering that causes the asymmetry of the flowering curve is in some cases an artefact due to the mild winter climate in which the plants are being grown. A related example is Ulex europaeus (Gorse), which is discussed below.

\section{CLASS C: MORE THAN ONE FLOWERING PERIOD}

Designating a flowering curve as comprising more than one flowering period is clear enough in cases like Daphne tangutica (92A) in Fig. 7 where no flowers have been

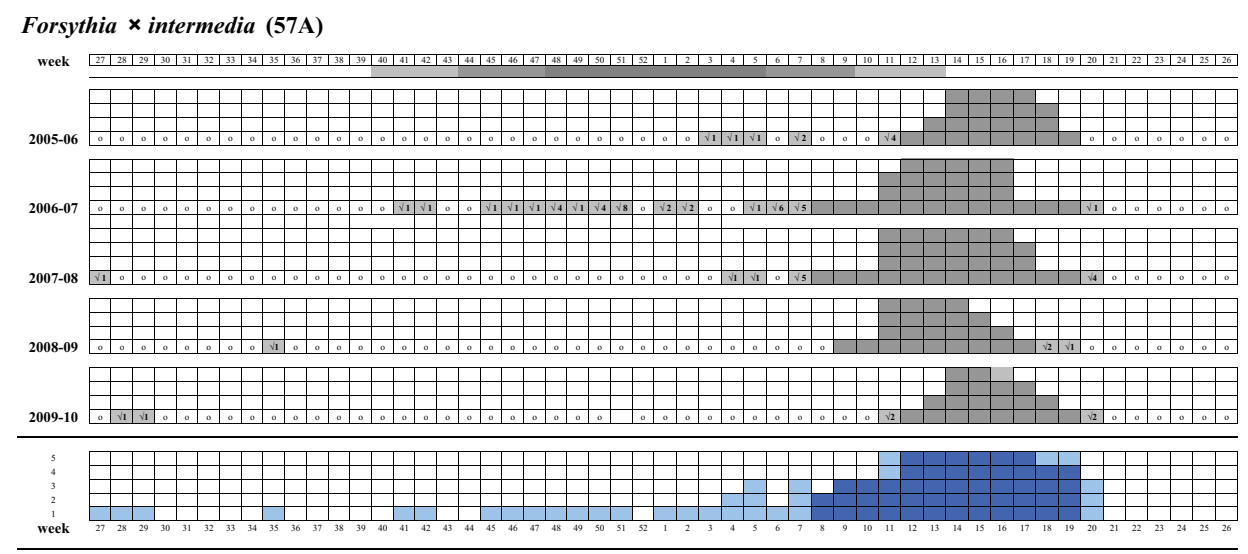

Fig. 6 Example of Sub-class B2: Forsythia $\times$ intermedia (57A). 
recorded in the gaps between the two flowering periods. But there are similar examples in which the two flowering periods are more or less linked by sporadic flowering in one or both gaps, and it seems sensible to include these cases in Class C.

Sub-class C1 includes all those accessions with well separated disjunct flowering periods (see Fig. 7). There are five accessions in five taxa - Daphne tangutica (92A), Lychnis viscaria, Muscari armeniacum (41A), Primula japonica and Rhododendron decorum (12D). A notable feature of Daphne tangutica (92A) is the rather wellsynchronised end of the main spring flowering period, possibly due to photoperiod regulation. There are too few observations to say that the beginning of the second flowering period is equally abrupt, but there does appear to be a well-defined 'summer gap' in flowering, in weeks 22-30.

Two further sub-classes are distinguished by closeness of the two flowering periods to each other. Sub-class C2 includes accessions in which the summer gap is much shorter than the winter gap (see Fig. 8). In this sub-class there are ten accessions in eight taxa - Arabis alpina (40A), Campanula poschkaryana, C. versicolor, Choisya ternata (17D), Cistus creticus (22B, 22D), Enkianthus campanulatus (92A), Primula poissonii and Weigela middendorffiana. In the case of Weigela middendorffiana (09A) all the years have a short but flowerless summer gap of about five weeks, while in Campanula versicolor (45A) the gap is filled or almost filled in two of the three years.

The summer gap in Weigela middendorffiana is particularly puzzling. Further observations are needed to confirm the impression gained by our records. If the pattern is confirmed, an explanation must be sought. Possible light on the matter may be shed by comparing it with what happens in some Araliaceae, for instance Hedera and Fatsia. In these genera, the terminal umbels can flower more or less simultaneously, forming the main peak in the flowering curve, and after an interval the subterminal umbels on each branch may flower, and if they are fairly well synchronised a second peak in the flowering curve is formed. Close inspection will be required to see whether Sub-class $\mathrm{C} 2$ taxa are behaving in a similar way.

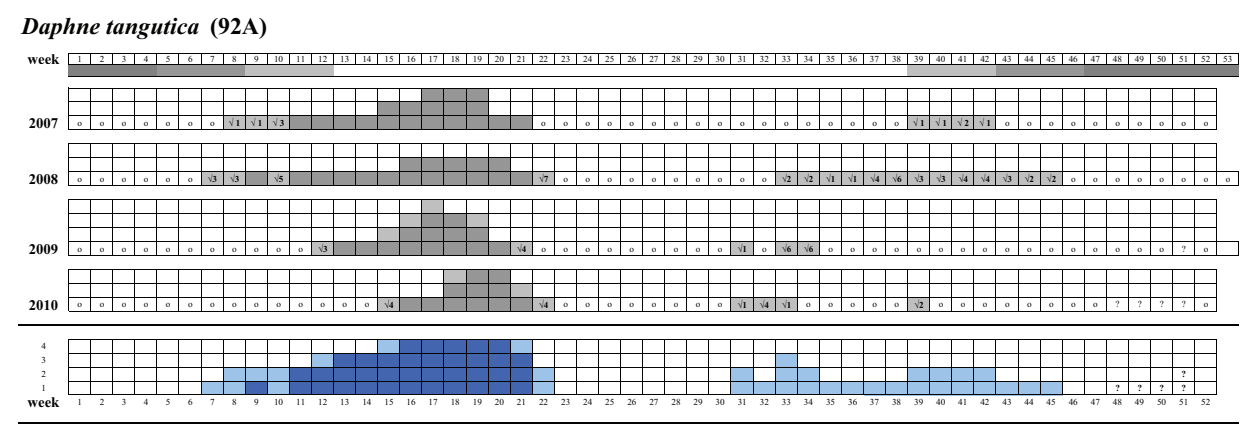

Fig. 7 Example of Sub-class C1: Daphne tangutica (92A). 

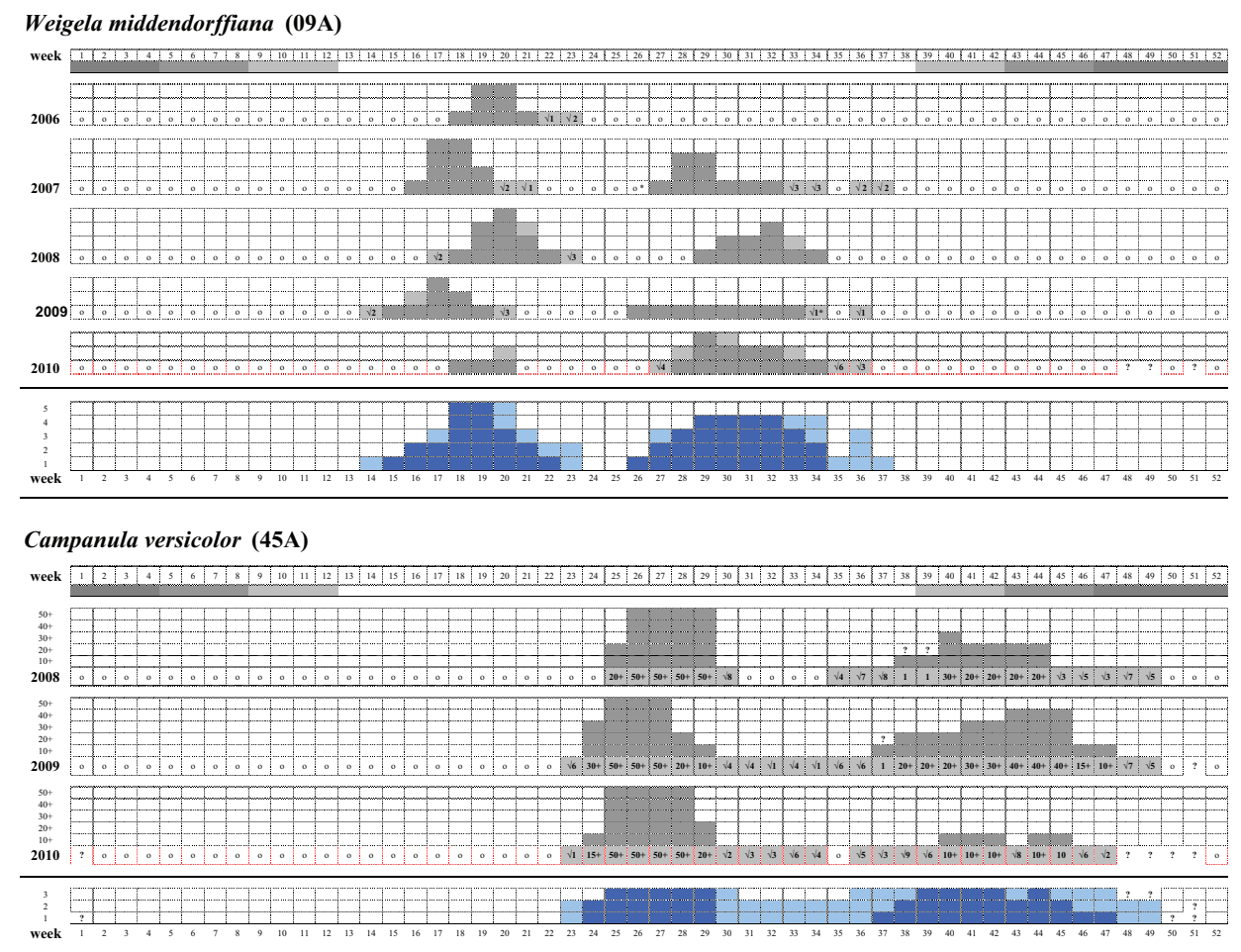

Fig. 8 Examples of Sub-class C2: Weigela middendorffiana (09A) and Campanula versicolor (45A).

Rhododendron lutescens (06C)

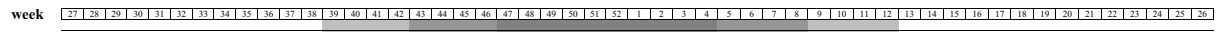
2006-07

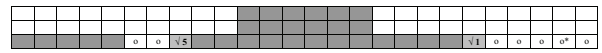

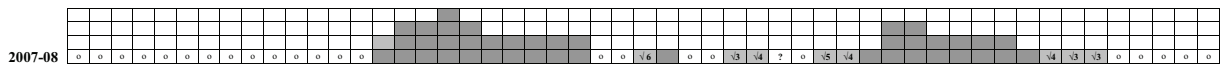

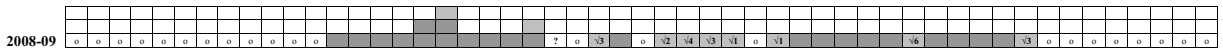

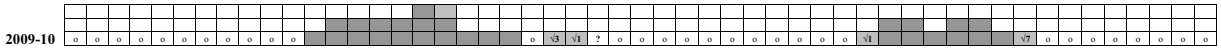

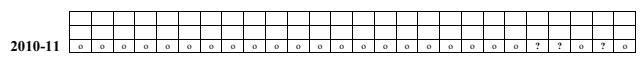

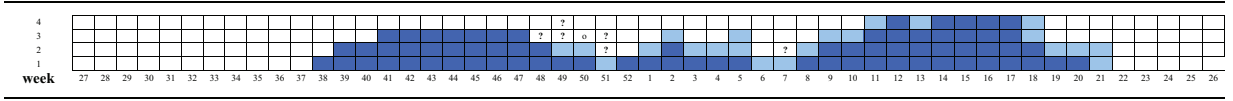

Fig. 9 Example of Sub-class C3: Rhododendron lutescens (06C).

By contrast Sub-class $\mathbf{C 3}$ suggests a closer connection between the two flowering periods through the winter, as shown in Fig. 9. This sub-class contains six accessions and six taxa - Daphne tangutica (92C), Eucalyptus gunnii (01A), Jasminum nudiflorum (06B), Rhododendron lutescens (06C), R. racemosum (84B) and Ulex europaeus (54A). 
Most or all members of this group show some continuity between the two flowering periods. Like Sub-class B2, these can also be considered to be 'mediterranean-type'.

Fig. 10 shows the flowering curves for Ulex europaeus plotted in two ways. The upper diagram shows the continuity through winter of admittedly sometimes rather ill-defined autumn and spring main flowering periods. The lower diagram, on the other hand, emphasises the well-synchronised end of flowering in weeks 26-27, close to the summer solstice, and the less well-defined start of flowering from week 36 onwards, leaving a summer gap of at least nine weeks in this particular accession (which is a single bush). The synchronised end of flowering suggests photoperiod regulation, possibly mediated through other functions - such as vegetative growth, seed and fruit maturation, or development of the next generation of flower buds - via some mechanism such as resource switching. The biological basis of this species' flowering behaviour was discussed in Harper \& Morris (2007) with reference to the study by Tarayre et al. (2007).

Fig. 11, by contrast, suggests that Jasminum nudiflorum (06B) has a more synchronised start than end of flowering. As in Fig. 10, flowering begins around week 37 and ends around week 26, near the summer solstice, although in most years the summer gap is much longer than nine weeks. (Another accession of this species belongs in

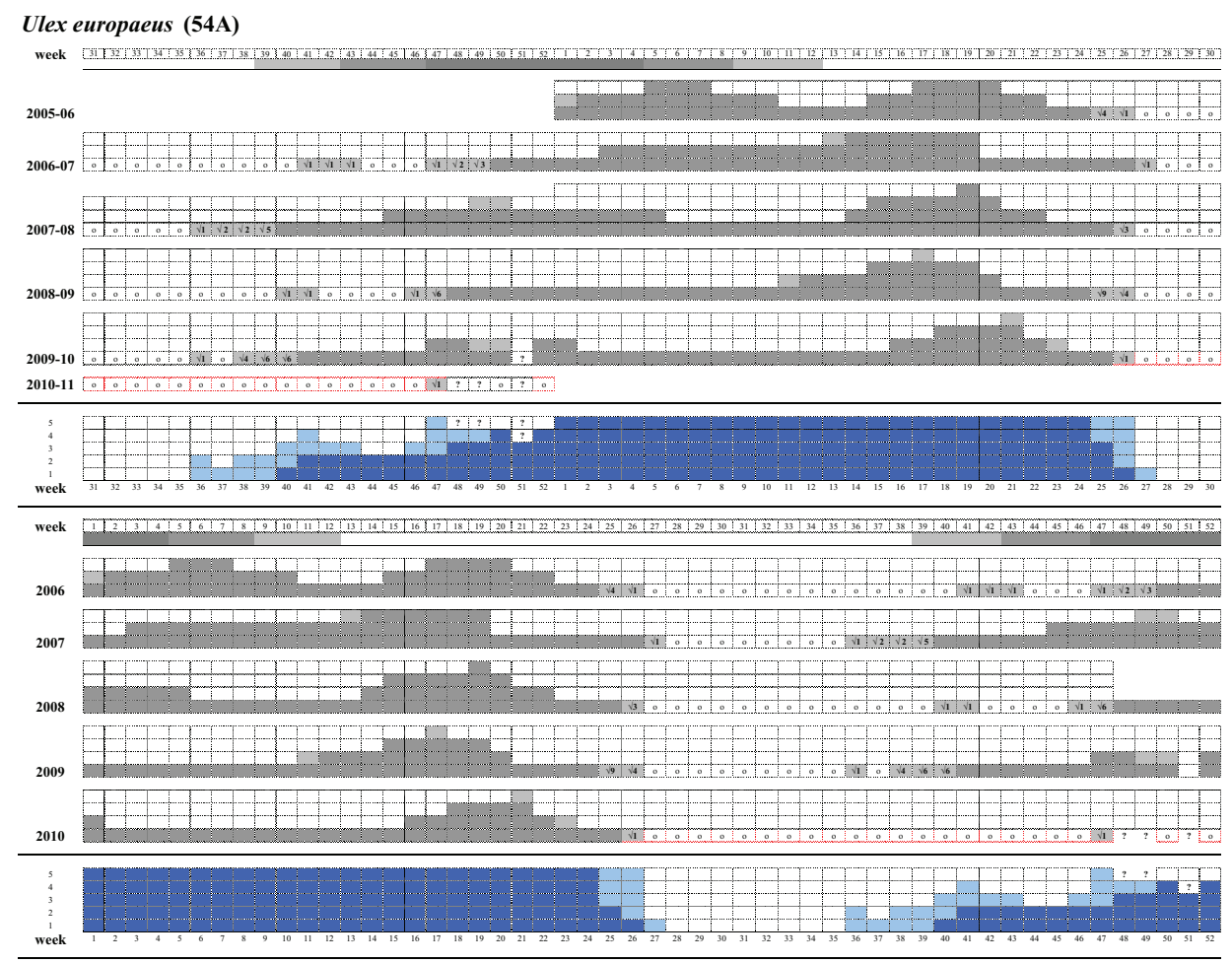

Fig. 10 Ulex europaeus (54A) Sub-class C3. 
sub-class A3, because the flowering curves do not indicate a clear differentiation into two flowering periods.)

The sometimes ill-defined nature of the two flowering periods in this sub-class suggests that inclement weather in winter may be temporarily suppressing flowering on an ad hoc basis, so creating a winter gap. In other words absence of bad weather, whether or not due to climate change, would lead us to expect continual flowering over an extended period from autumn through to spring, as a result of the successive opening of new buds. This is supported by the frequent observation of flowering resuming soon after improvement of the weather following the destruction of the earlier flowers in the bad weather.

Sub-class $\mathbf{4}$ comprises those accessions showing some degree of continuity between the two flowering periods in both summer and winter. At present only one taxon (two accessions) clearly fits this description - Lithodora zahnii (73B, 73D) (see Fig. 12).

Lithodora zahnii (73D) has a prominent spring and early-summer main flowering period, with an extended period of secondary flowering through most of the second half of the year. In one year out of three the winter gap is absent, and in one year out of three the 'summer gap' is likewise missing. It might be tempting to explain this fairly symmetrical pattern in terms of a stenophotoperiodic effect, in other words extremes of daylength, both short and long, suppressing floral initiation; but then it would be expected that the gaps would be displaced somewhat later than the summer and winter

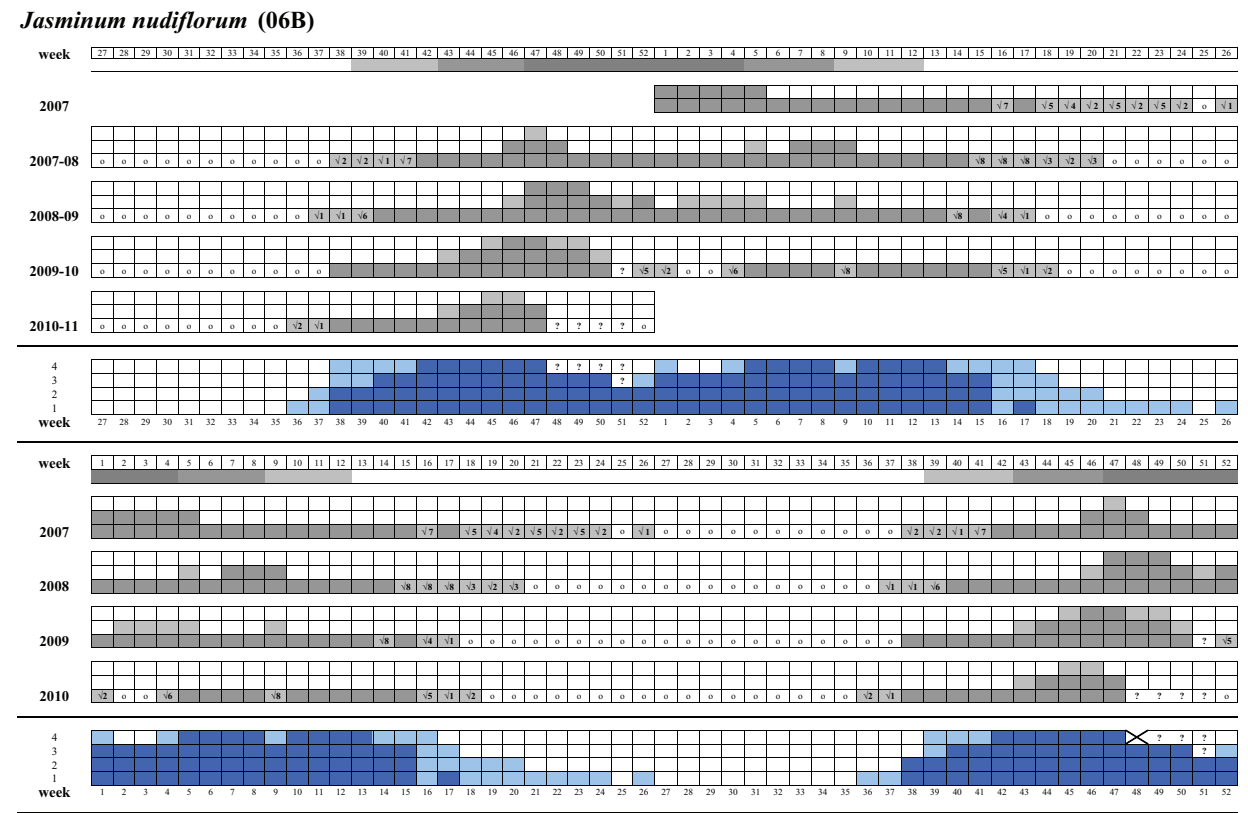

Fig. 11 Jasminum nudiflorum (06B) Sub-class C3. 


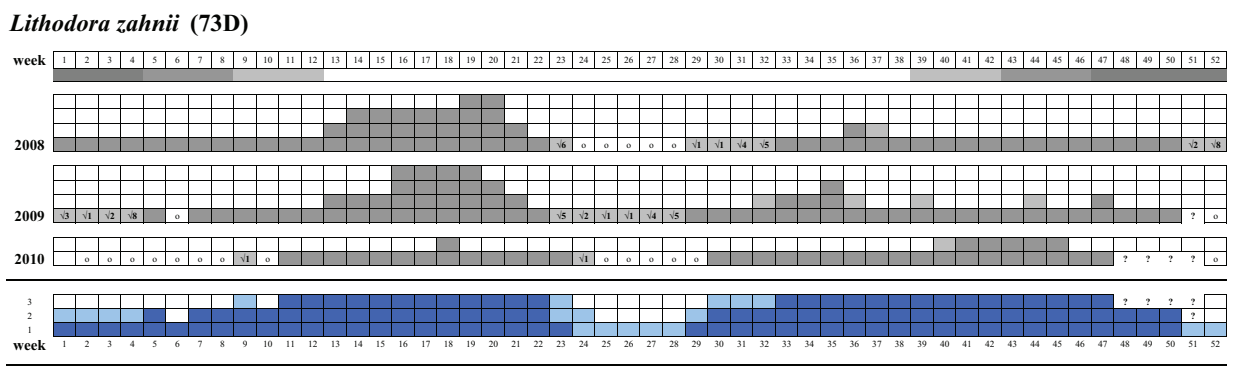

Fig. 12 Example of Sub-class C5: Lithodora zahnii (73D).

solstices. However, the summer gap is centred almost exactly on the summer solstice - and a similar though slightly less clear picture emerges from Lithodora zahnii (73B). The daylength hypothesis does not seem particularly convincing, and the mystery of the summer gap deepens.

Three problematic accessions are Choisya ternata (17B), Prunus laurocerasus 'Otto Luyken' (two bushes separately monitored) and Rhododendron ponticum (39A) (see Fig. 13). The late flowering season of $R$. ponticum (39A, Fig. 13) is rather well defined, and there is sporadic flowering in both the summer and winter gaps. Although records are not available from other accessions of $R$. ponticum, casual observation suggests that late flowering generally does not occur at all or not strongly in normal examples. It may be significant that $R$. ponticum (39A) is a hybrid with unknown second parent. Further observations on $R$. ponticum (39A) may fill the gaps in the Aniśko diagram, to show that the plant has the potential to flower all year round, but it will be of interest if the spring gap (weeks 9-14) proves to be constant, as might be expected if the main flowering period cannot commence until some threshold (temperature and/or photoperiod) is crossed. Prunus laurocerasus 'Otto Luyken' similarly appears to have a constant gap just before the main flowering period, although more years of observation are required

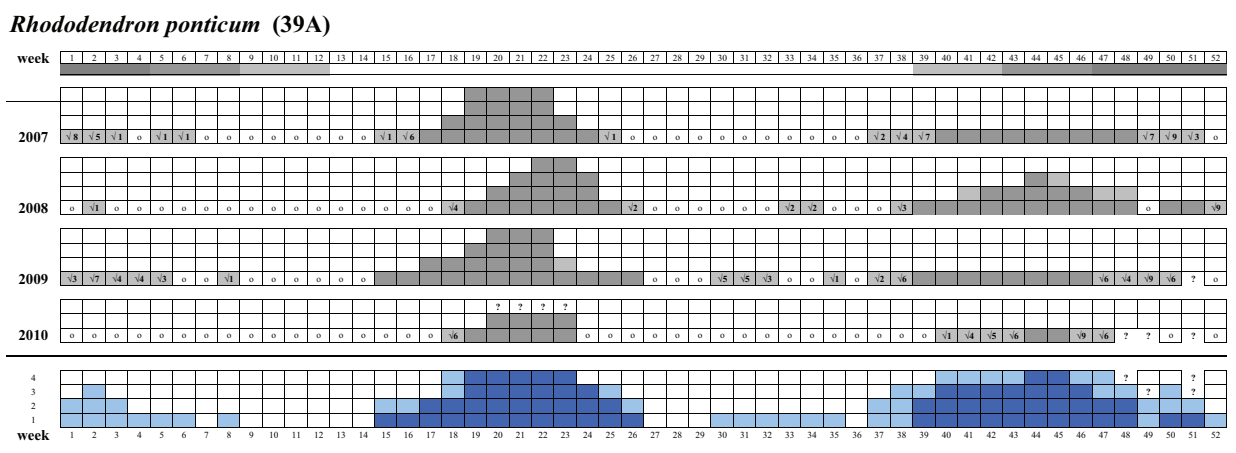

Fig. 13 Example of Sub-class C4: Rhododendron ponticum (39A). 
to confirm this pattern. A well-established constant gap just before the main flowering period might justify separation of a new sub-class.

\section{COMPARING FLOWERING IN EDINBURGH AND IN THE NATIVE RANGE}

An interesting example of intra-specific variation is Rhododendron dauricum (see Fig. 14), named after the area known as Dauria, south of Lake Baikal in central Siberia. Two accessions in our study are Rhododendron dauricum (20A), collected from the wild in Dauria (actually in the former Buryatskaya Autonomous Soviet Socialist Republic), and Rhododendron dauricum (41E), collected from the wild in Hokkaido, northern Japan. Unfortunately the latter has died, so that observations cannot be continued on this particular accession.

Both accessions have been classified as having asymmetric flowering curves, although the asymmetry is not particularly marked in 41E. What is striking is the difference in the flowering curves of the two accessions, not only in shape but also in timing. The main flowering period is not so different in the two bushes, but $20 \mathrm{~A}$ generally begins months earlier than 41E.

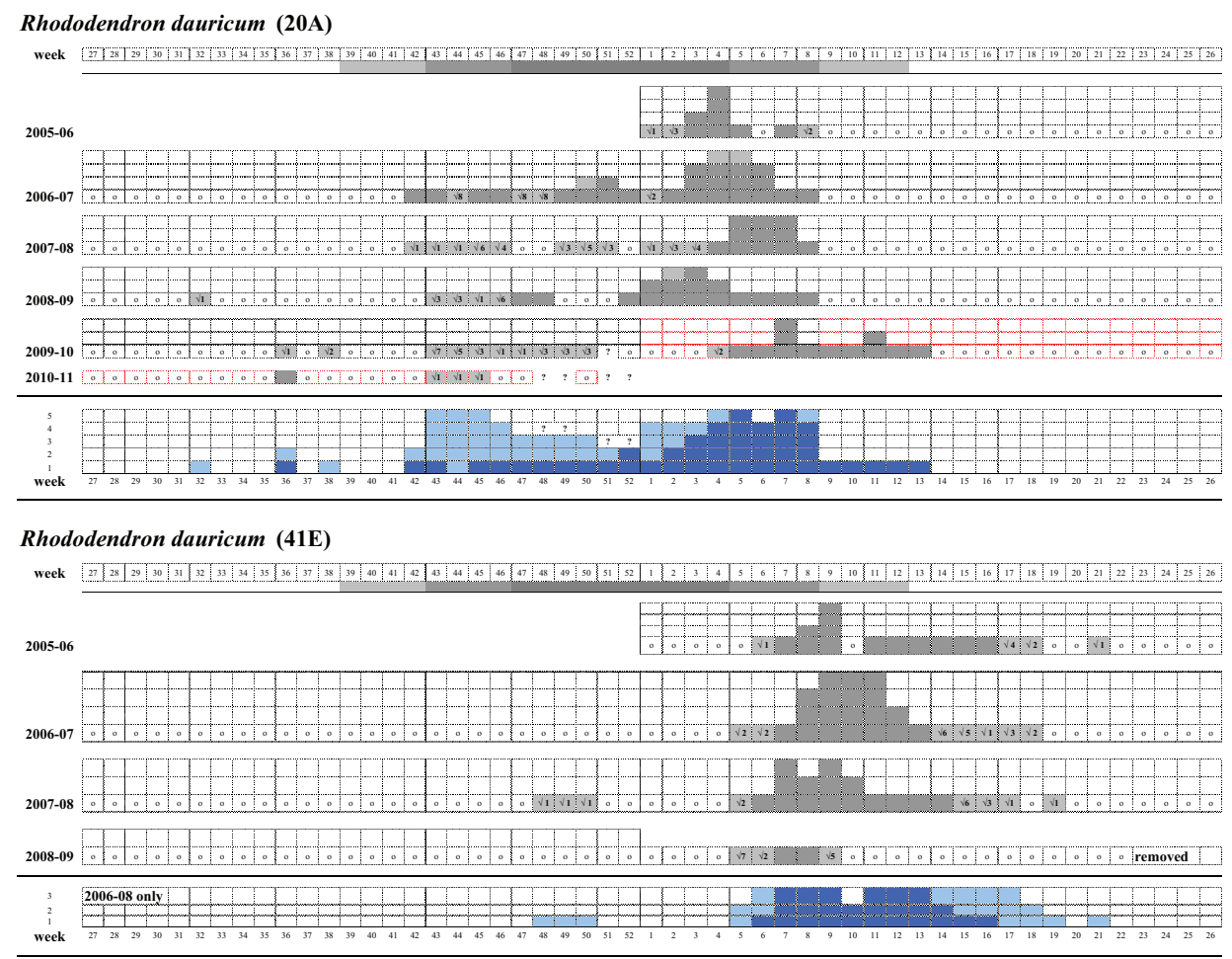

Fig. 14 Rhododendron dauricum (20A) Sub-class B2, from Dauria and Rhododendron dauricum (41E) Sub-class B1, from Japan. Note that the Aniśko diagram of 41E covers only 36 months, omitting early 2009. 
It is possible to speculate on the reasons for this difference: $41 \mathrm{E}$ comes from an island, with a climate presumably influenced by proximity to the ocean, and in that respect somewhat similar to Scotland, while 20A comes from the centre of a large continent, with a far more continental climate than Scotland's, and with long cold winters. It might be expected that plants growing in areas with a reliably long cold winter would need only a small chilling requirement when winter sets in, since low temperatures would prevent flowering until spring arrives many months later. A more oceanic climate, as in Hokkaido and Scotland, brings the risk that quick chilling in the autumn or early winter exposes the plant to the danger of flowering in subsequent warm spells in winter, with possible frost damage to flowers. In this case one might expect a stronger chilling requirement to have evolved as protection against this risk. So although the flowering behaviour of $R$. dauricum in the two native ranges may not be very different - in fact it flowers in Hokkaido in May (Iwatsuki et al., 1993) and in late April to June, sometimes in September, in the Soviet Union (Shishkin \& Bobrov, 1967) - the difference seen in Edinburgh could point to the difference in chilling requirement as an expression of adaptation to different climates in the native ranges.

On the strength of this example, we recommend that similar observations should be carried out at other botanic gardens which have well-documented accessions from different parts of a taxon's natural range, and results similar to those reported here may turn up in many other species. An elaboration of this approach could involve transplanting cloned material from one garden to another, or from the wild to a garden in a different climate, with observations made on the populations in the two (or more) areas.

A variant on this idea would be to bring together accessions of closely related species that have diverged from a common ancestor and now occupy different ranges. These might reveal how plants have adapted through geological time to climate change. The case of Cyclamen purpurascens (Harper \& Morris, 2007) is a case in point. While the timing of the end of flowering and leafing does not vary very much in Cyclamen, FFD and first-leaf date (FLD) are far more variable between species. FFD and FLD are so far advanced in $C$. purpurascens that only a short summer gap is left. Given that the range of $C$. purpurascens is Central Europe, well north of the main range of the genus, its early FFD and FLD may well be adaptations to the change in climate and/or other environmental conditions involved in the change of range.

\section{THE SUMMER-GAP MYSTERY}

The most unexpected finding in this study concerns the summer gap in flowering. A winter gap is not surprising, since interruption in flowering is expected when the weather is too bad for fragile flowers to remain in good condition, although it is surprising how some fragile-looking flowers, such as those of Rosmarinus officinalis, appear to sail through the worst of winter without even a gasp.

Our attention was drawn to the gardeners' and beekeepers' 'June gap' by a colleague at RBGE (McHaffie, pers. comm.), on showing her a printout of Fig. 15. She 


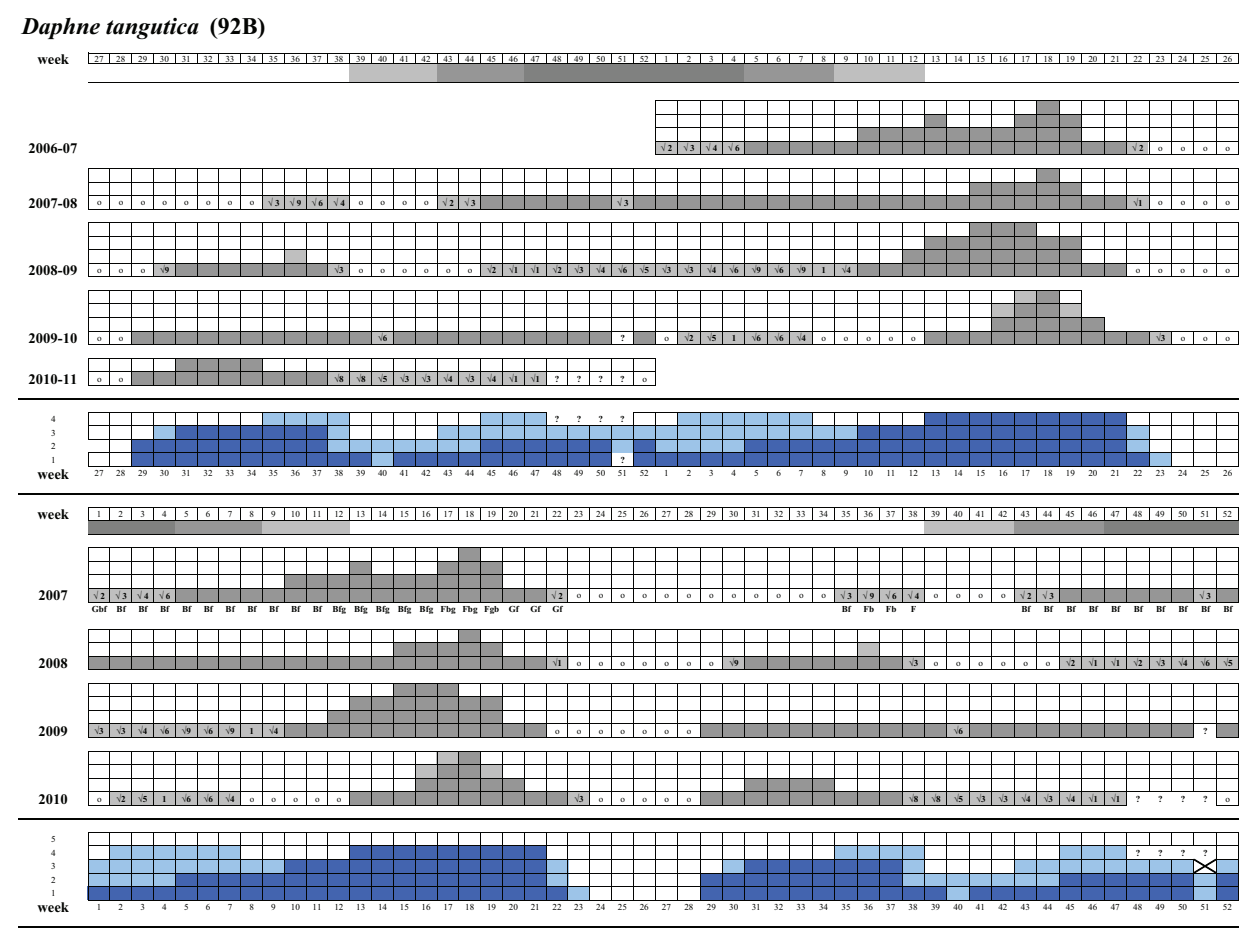

Fig. 15 Daphne tangutica (92B) Sub-class B2 (compare with Fig. 7).

told us that gardeners are sometimes short of plants that flower in June, while beekeepers often lack nectar sources for their bees at about the same time (Muir, 2011). It may be a coincidence, but if so it is a striking coincidence, that a summer gap - and often quite a short one - is found in a variety of species in the present study. These include, with approximate timing of the gap, Arabis alpina (40A) (weeks 25-29), Choisya ternata (17B) (28-30), Daphne laureola (88A) (23-31), D. tangutica (23-28; 23-30; 27-31), Forsythia $\times$ intermedia (57A) (21-26), Lithodora zahnii (73B) and (73E) (24; 24-28), Ulex europaeus (54A) (28-35), Viburnum tinus (21-30+) and Weigela middendorffiana (24-25; 23-25). There is no other time of year rivalling mid summer for such a coincidence of gaps in flowering curves.

Perhaps some light can be shed on the phenomenon by Fig. 16, which is based on five accessions of Hamamelis mollis, two of which are cv. 'Pallida'. The individual Aniśko diagrams of the five accessions are shown in the upper part of the diagram in order to check whether they are sufficiently similar to justify adding all the results to produce the composite diagram below. The heights of the columns in the composite diagram can be used as an estimate of the probability of flowering in each week. It varies from near or actually 100 per cent in January to near or actually zero in weeks 30-34. An important difference from the examples in Figs 7, 10 and 15 is that neither the end 
nor the start of flowering is synchronised from year to year, suggesting that photoperiod is not involved as a trigger. And yet there is a summer gap in probability of flowering, albeit only in terms of minimum probability.

Photoperiod regulation could be involved if there is an inverse quantitative relation between probability of flowering and daylength, assuming a development of about seven weeks between floral initiation (or some other developmental stage influenced by day or night length) and the flowers opening. In other words the probability of flowering progressively declines as days lengthen (and nights shorten).

The probabilistic summer gap in Hamamelis flowering seems, however, not to resemble closely the other examples listed above, in which the summer gap is rather short and well defined. The 'mystery' of the summer gap consists in the fact that it is not nearly so easy to suggest what might be going on as it is in the case of the main patterns of flowering curve described earlier. It should be emphasised that further observations are needed to demonstrate that the short summer gap is in fact objectively observable; then, if it does prove to be a real phenomenon, two kinds of explanation are required. What advantage does it bring to the plants, if any? And what mechanisms cause the summer gap?

It is difficult to see what advantage to the plants there could be to stop flowering for a short period of only a month or slightly longer. This is particularly the case in Weigela middendorffiana (see Fig. 8), in which the second flowering period appears to follow the

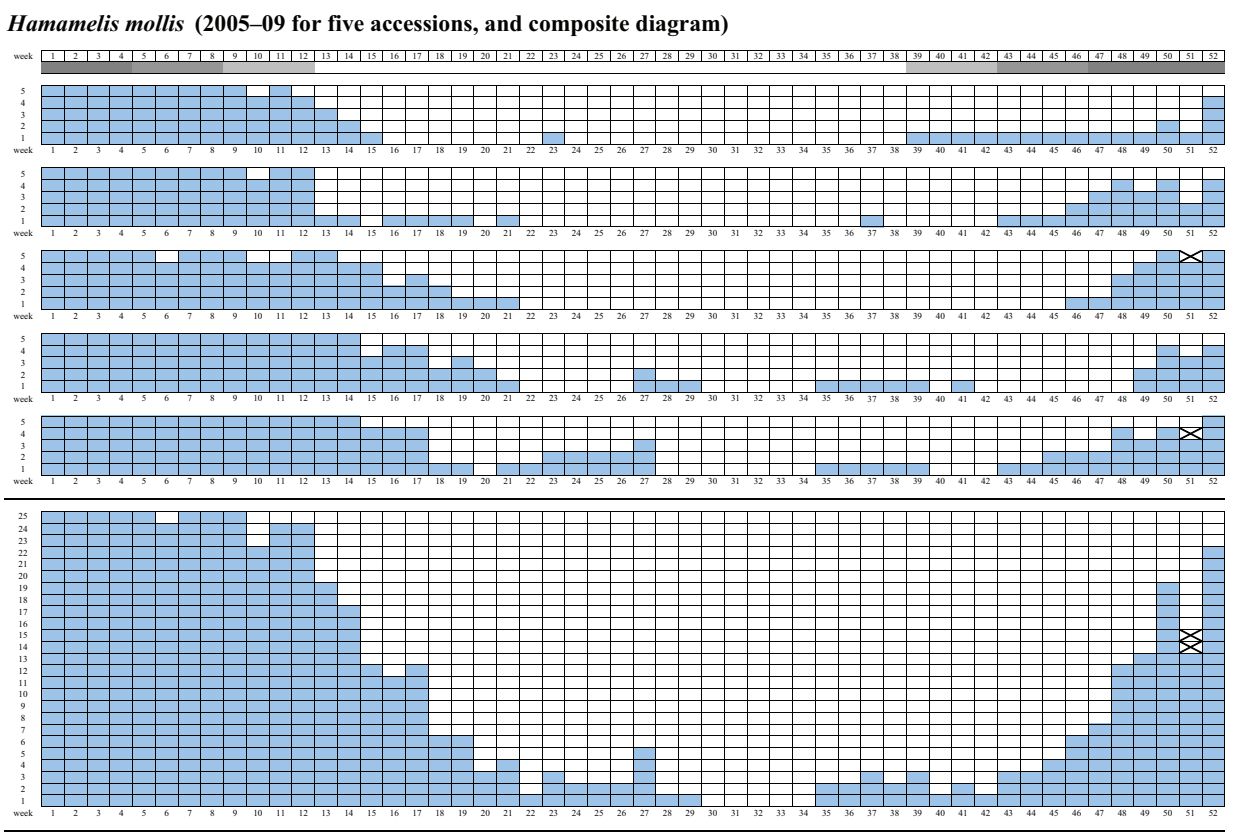

Fig. 16 Aniśko diagrams of Hamamelis mollis from top to bottom (02A), (02C), (04B), (11A) and (94A) and a composite diagram of all accessions combined. 
first after an absurdly short gap, and moreover a gap which is not well synchronised from year to year. On the other hand, most of the taxa with a short summer gap are non-native plants growing in Edinburgh, and it is possible that the short gap has no adaptive significance, but is an artefact resulting from an early start to flowering in Edinburgh due to the unusual climate in which the plants are growing. In their native ranges the summer gap may be much longer and may be adaptive if it coincides with a dry season of the year when flowering would not be possible or would not result in sufficient viable seed. It would be useful to compare the flowering behaviour of these plants in Edinburgh with that in their native ranges. In fact transplanting cloned material to different sites might produce revealing results and would incidentally shed light on how these plants react to climate change. If flowering in the native range is triggered by autumn rains and/or autumn temperatures, then the cool damp Edinburgh summer may permit flowering to begin early.

As to mechanisms, it might be plausible to consider photoperiod regulation of the end of flowering, where a given day- or nightlength acts as a trigger or threshold. In this case, what would happen to a plant transplanted to a higher latitude? A given daylength occurs earlier in higher latitudes on account of daylength at mid summer being longer than at lower latitudes, so - other things being equal - this should cause flowering to end in Edinburgh earlier than in, say, the Mediterranean area. On the other hand, if photoperiod acts by regulating floral initiation, then lower temperatures at higher latitudes might considerably extend the period between initiation and fading or falling of the flower, and this might account for the late end of flowering of 'mediterranean-type' plants in Edinburgh. No doubt we could speculate on other quite different explanations, and this would indeed be a useful exercise. At present the aim is to establish the facts, and if these raise interesting scientific questions it is to be hoped that other investigators will explore them in more detail.

A number of other taxa, not showing a short summer gap, also terminate flowering in a rather synchronised manner near the summer solstice. Examples include Daphne tangutica (92A) weeks 21-22 (see Fig. 7) and (92B) weeks 21-23 (see Fig. 15); Forsythia $\times$ intermedia (57A) weeks 19-20 (see Fig. 6); Muscari armeniacum (41A) weeks 22-23, (82A) weeks 22-23 and (98A) weeks 21-23; Oxalis acetosella (16A) weeks 21-22; Pieris japonica (33A) weeks 19-21; and Viburnum grandiflorum (03D) weeks 19-20 (see Fig. 4). So it may be that photoperiod-regulated termination of flowering in summer is a rather common phenomenon.

This paper has referred to three different forms of summer gap in flowering, namely the variable-date 'weigela' type, the probabilistic 'hamamelis' type and the year-to-year invariant 'daphne' type. If they can be confirmed as phenomena, it is likely that they are caused by different biological mechanisms. Further investigation is warranted.

\section{CONCLUSION}

The provisional classification of flowering curves is no doubt highly imperfect, and improvements are to be expected based on further observations. But the classification 
does at least help us identify important variables to take into account - in particular the duration and shape of the flowering curves, their timing, the number of flowering periods, how well separated they are and the synchronicity from year to year of the start and end of each flowering period.

It is also evident that there is considerable variation between taxa and within some taxa. In other words the phenomena are complex, and mechanisms are probably complex too. There is no convenient short formula to summarise how plants are likely to respond to climate change: each plant, and indeed sometimes each individual plant or genotype, needs to be considered on a case-by-case basis. Only when a large number of individual cases are well understood will it be possible to reach broad generalisations, helping us to predict how any given plant or taxon is likely to respond to climate change.

The general lack of correspondence between the flowering-curve and taxonomic classifications can be illustrated by Rosaceae: Malus sieboldii belongs to Sub-class A1, Potentilla fruticosa to Sub-class A3, Fragaria californica to Sub-class B1 and Prunus laurocerasus 'Otto Luyken' to Sub-class C4.

If very few firm conclusions can be drawn from the work described here, one thing is clear: the simple methods used at RBGE are revealing interesting patterns that need to be confirmed and extended to a wider range of species. Fascinating scientific questions are also emerging. It is strongly recommended that other botanic gardens conduct similar monitoring projects, preferably using methods that enable results to be compared between gardens. Even more valuable results would be obtained if gardens exchanged cloned material and grew it so far as possible in comparable conditions, because this is a simple way of subjecting plants to climate change, with useful results obtainable within only a few years. As seen from the Aniśko diagrams in this paper, results can be obtained by recording merely presence or absence of flowering on individual woody plants or small patches of herbs every week, and this is something that can be done in almost any situation.

It would be particularly interesting to have confirmation of the short summer gap in the plants growing at RBGE, together with comparison of their flowering curves with the same taxa in their native ranges in different climates.

Another beneficial result from Aniśko diagrams when compiled over several years is the kind of probability curve illustrated in Fig. 16. Sigmoid 'valley sides' suggest a possible quantitative relation with daylength, whereas photoperiod regulation acting as a threshold would be expected to produce a 'canyon', with steep sides. In both cases, since daylength does not change appreciably when climate changes (except through the possible influence of cloud cover), we would not expect photoperiod-regulated summer flowering to change much in response to climate change.

\section{ACKNOWLEDGEMENTS}

The pilot project was set up by Janette Latta, ER and Kenny Anderson, with observations being made by GH. From January 2005 to 2010 the monitors were Lyn Blades, Sandra Stewart, Maria Lee and ER, with GH entering the observations into spreadsheets and 
carrying out the analysis. The project is being continued by LB, ML and SS. Stephan Helfer manages the phenology projects at RBGE, and Phil Lusby, Greg Kenicer, Heather McHaffie and Christine Thompson have provided useful information and comments. Thanks are due to all who have made the Weekly Project a success so far - including the horticulture staff who maintain the plants - and it is hoped that the RBGE Weekly Project will continue making observations long into the future.

\section{REFERENCES}

ANIŚKO, T. (2008). When Perennials Bloom: An Almanac for Planning \& Planting. Portland, OR and London: Timber Press. 510pp.

BLADES, L., HARPER, G.H., HELFER, S., LEE, M.L., ROGERS, L. \& STEWART, S. (2008). Rapid-survey methods for flowering phenology. Sibbaldia 6, 163-179.

HARPER, G.H. (2010). Lessons from phenology: an interim report. Sibbaldia 8, 149-164.

HARPER, G.H., MANN, D.G. \& THOMPSON, R. (2004). Phenological monitoring at Royal Botanic Garden Edinburgh. Sibbaldia 2, 33-45.

HARPER, G.H. \& MORRIS, L. (2007). Flowering and climate change - part II. Sibbaldia 5, $25-42$.

IWATSUKI, K., YAMAZAKI, T., BOUFFORD, D.E. \& OHBA, H. (1993). Flora of Japan, vol. IIIa. Tokyo: Kodansha.

JACKSON, J.E. (2003). Biology of Apples and Pears. Cambridge: Cambridge University Press. 488pp.

KÖRNER, C. (2006). Significance of temperature in plant life. In: MORISON, J.I.L. \& MORECROFT, M.D. (eds). Plant Growth \& Climate Change. Oxford: Blackwell Publishing Ltd.

MUIR, S. (2010). What is the 'June gap'? How do you know it exists in your area? The Scottish Beekeeper 88, 163.

SHISHKIN, B.K. \& BOBROV, E.G. (1967). Flora of the USSR, vol. xviii. Jerusalem: Israel Program for Scientific Translations.

TARAYRE, M., BOWMAN, G., SCHERMANN-LEGIONNET, A., BARAT, M. \& ATLAN, A. (2007). Flowering phenology of Ulex europaeus: ecological consequences of variation within and among populations. Evolutionary Ecology, 21, 395-409. 